\title{
Teaching Method Preferences of First Year Medical Students in a Medical College in India
}

\author{
Ashwini K Shetty and Amrith Pakkala*
}

Dept of Physiology, MVJ Medical College \& Research Hospital,Hoskote, Karnataka, India

\begin{abstract}
Background: Experiments in labs are usually taught using personality models, information processing models, social interaction models and instructional preference models. This study uses the VARK- visual, auditory, read/write, and kinaesthetic inventory to gather information as per instructional preference model for assessing learning preferences among first MBBS students with reference to hematology experiments.

Aim: This study is designed to evaluate and compare instructional learning style preferences of first and second semester medical students in a peripheral medical college in India

Method: This study was conducted on first and second semester MBBS students with each group having 75 students each. VARK inventory version 7.1 was administered to determine the preferred instructional mode based upon the four sensory modalities- visual, auditory, read/ write and kinaesthetic with reference to hematology experiments.

Results: $80 \%$ of the first semester students had unimodal learning preferences out of which $10 \%, 50 \%, 5 \%$ and $15 \%$ students preferred visual, auditory, read/write and kinaesthetic modes respectively. In comparison, significantly higher percentage (50\%) of second semester students had multimodal learning preferences. Their unimodal learning preference was $5 \%$ visual, $5 \%$ auditory, $5 \%$ read $/$ write and $15 \%$ kinaesthetic modes.

First semester students' auditory instructional style as the most preferred method, whereas the second semester students preferred the kinaesthetic mode.

Conclusion: With the passage of time in the medical course, students adapt to a multimodal method of instruction.It is therefore in the interest of students to strengthen, encourage and adopt a multimodal approach to lab teaching rather than resorting to conservative unimodal approach.
\end{abstract}

Keywords: Learning Preference in Hematology, VARK, MBBS Students

\section{Introduction}

Workers in the field of education have generally opined that every individual has a specific innate learning style and learning is more effective if instruction is delivered by this method ${ }^{1}$. This assumption has a physiologic basis depending upon the sensory modality students prefer to use while assimilating information. Teaching methodologies in medical colleges has to be in line with learning preferences of the present generation of medical students. The VARK visual, auditory, read/write and kinaesthetic questionnaire is widely accepted for assessing instructional preferences and is therefore a valuable tool in assessment of student learning preferences ${ }^{2}$. VARK version 7.1 is the latest in this series capable of assessing four modalities of above mention learning preference parameters. It has been demonstrated by earlier workers that visual preference in the context of learning preferences includes use of diagrams and pictures, graphs and flow charts. Auditory preferences include hearing discussions, lectures and tutorials. Read/ write preferred reading printed material. Simulation of real life experiences, field trips, demonstrations, workshops and hands on experiences are preferred by kinaesthetic learners.

Unimodal learners in this study are that group of students who prefer a single method of information presentation, whereas multimodal learners prefer more than one method. VARK inventory method has been widely used in various countries to assess learning method preferences. Learning styles of students in the medical college is bound to change over a period of time. Students from a diverse background gain admission in a peripheral medical college in India. It would be interesting to know and compare their learning method preferences at the time of joining the medical college in the first semester with that in the second semester after a short duration of exposure to medical teaching.This study is designed to evaluate and compare instructional learning style preferences of first and second semester medical students with reference to hematology experiments using 7.1 version of VARK questionnaire. 


\section{Material and Methods}

This study was conducted on medical students studying at PES Institute of Medicine, Kuppam. Ethical clearance was obtained from the institutional ethics committee. Students of the first semester $(n=100)$ participated in the study. Voluntary informed consent was obtained for the study. VARK version 7.1 questionnaire was administered. The questionnaire consists of 16 multiple choice questions and it measures four perceptual learning preferences (Visual, auditory, reading/writing and kinaesthetic). Each question carried four options. Participants were permitted to choose one or more than one options as found suitable. 100 respondents completed the questionnaires. Questionnaires were evaluated on the basis of previously validated scoring instructions available on the VARK site ${ }^{2}$.

This method was repeated to assess the responses of the same set of students when they were in second semester. Statistical analysis was done to calculate percentage of students with unimodal and multimodal preference in both sets, percentage of students in each category of learning style preference in the two semesters, dominant learning preference in each study group using chi square test.

\section{Results}

VARK inventory results for the first and second semester medical students are shown in table 1 and graph in figure 1

The data shows that $80 \%$ of the first semester students had unimodal learning preferences out of which $10 \%, 50 \%$, $5 \%$ and $15 \%$ students preferred visual, auditory, read/ write and kinaesthetic modes respectively. In comparison, significantly higher percentage $(50 \%)$ of second semester students had multimodal learning preferences. Their unimodal learning preference was 5\% visual, 5\% auditory, $5 \% \mathrm{read} /$ write and $15 \%$ kinaesthetic modes. First semester students' auditory instructional style as the most preferred method, whereas the second semester students preferred the kinaesthetic mode. The number of second semester students preferring the auditory method was was significantly lower than the first semester. Students in the second semester had a broader outlook in their learning preferences as encompassed in their choice for multimodal learning methods.

\section{Discussion}

This study was designed to evaluate and determine the learning preference of first semester students of medicine with that in the second semester. Hematology experimental lab teaching was used as a reference. Learning preferences of students help teachers to practise effective teaching methods. The present study revealed that the most preferred unimodal learning style in first semester students was auditory. These findings are similar to other Indian workers like Jindal et $\mathrm{a}^{[3]}$, Shah et $\mathrm{a}^{\left[{ }^{[4]}\right.}$. This is in contrast to similar studies in the West were read/write method was preferred by fresh students. Malaysian students had preferred kinaesthetic method in one of the studies ${ }^{[5]}$. The difference in preferences in this group of fresh medical students is most likely due to their earlier training methods before entry into the medical college. A similar view is opined by workers in this field ${ }^{[6]}$. Gender influence on learning style methods were not studied here as there is a lot of difference of opinion on this ${ }^{[4]}$. The present study revealed that learning style preferences were significantly different in second semester as compared to the first. The learners preferred unimodal methods in the first semester as compared to the second where a majority preferred multiple combinations of instructional methods. Lack of adequate teaching infrastructure and trained manpower in developing countries results in unimodal auditory methods being used predominantly in the school level. Training in a medical college encompasses multiple modes of teaching methodologies including tutorials and practical training. Hence there is more of a multimodal exposure in the medical college.

\section{Conclusion}

It is important to know the learning preferences of the present generation of medical students in order to understand the felt need of students. Preferences in instructional methods varies with the passage of time in the medical college. With the passage of time in the medical course, students adapt to a multimodal method of instruction. It is therefore in the interest of students to strengthen, encourage and adopt a multimodal approach to lab teaching rather than resorting to conservative unimodal approach.

Table 1: Comparison of Unimodal and Multimodal Instructional Methods.

\begin{tabular}{|c|c|c|c|c|c|}
\hline Semester- MBBS & Visual \% & Auditory \% & Read/Write \% & Kinaesthetic \% & Multimodal \% \\
\hline First & 10 & 50 & 5 & 15 & 20 \\
\hline Second & 5 & 5 & 5 & 15 & 50 \\
\hline P value & 0.400 & 0.0001 & 0.607 & 0.605 & 0.001 \\
\hline
\end{tabular}




\section{References}

1. Keefe JW , Learning style: theory and practice. Virginia; National association of secondary school principals; 1987

2. Fleming ND. VARK: A guide to learning styles; www. varklearn.com/english/page.asp?p_questionnaire; 2007

3. Manisha Jindal, Poonam Kharb, Samanta PP. Comparative analysis of instructional learning preferences of medical students of first and seventh semester; 2013, International Journal of Physiology vol 1 no.1 32-36
4. Shah C, Joshi N, Mehta HB, Gokhale PA. Learning styles adopted by medical students. International Research Journal of Pharmacy. 2011; 2(12):227-229

5. Kumar L, Voralu K, Pani S, Sethuraman K. Predominant learning styles adopted by AIMST university students in Malaysia South East Asian Journal of Medical Education. 2009; 3: 37-46

6. Nuzhat A, Salem RO, Mohammad SA, Nasir Al Hamdan. Learning style preferences of medical students: A single institute experience from Saudi Arabia. Int J Med Edu. 2011;2:70-73

*Corresponding author:

Dr. Amrith Pakkala, MD Professor, Dept of Physiology,Shridevi Institute of Medical Sciences \& Research Hospital,Tumakuru, Karnataka, India

Financial or other Competing Interests: None.

http://www.aamsjournal.com 